\title{
MANAGEMENT COMMITMENT AND SAFETY TRAINING AS ANTECEDENT OF WORKERS SAFETY BEHAVIOR
}

\author{
Zuraida Hassan ${ }^{1 *}$, Chandrakantan Subramaniam², Md. Lazim Mohd. Zain ${ }^{3}$, Subramaniam Sri
} Ramalu $^{4}$, Faridahwati Mohd Shamsudin ${ }^{5}$

1 School of Business Management, College of Business, Universiti Utara Malaysia, Malaysia

Email: h.zuraida@uum.edu.my

2 Co-operative and Entrepreneurship Development Institute, Universiti Utara Malaysia (UUM), Malaysia

Email: chandra@uum.edu.my

3 School of Business Management, College of Business, Universiti Utara Malaysia, Malaysia

Email: lazim@uum.edu.my

4 Othman Yeob Graduate School, Universiti Utara Malaysia (UUM), Malaysia

Email: subra@uum.edu.my

5 School of Business Administration, Al Akhawayn University (AUI), Morocco.

Email: F.MohdShamsudin@aui.ma

Corresponding Author

\section{Article Info:}

\section{Article history:}

Received date: 05.11 .2020

Revised date: 10.11 .2020

Accepted date: 20.11 .2020

Published date: 01.12 .2020

\section{To cite this document:}

Hassan, Z., Subramaniam, C., Zain, M. L. M., Ramalu, S. S., \& Shamsudin, F. M. (2020). Management Commitment And Safety Training As Antecedent Of Workers Safety Behavior. International Journal of Supply Chain, Operation Management and Logistics, 1 (2), 01-20.
Abstract:

The manufacturing sector in Malaysia is categorized as one of the dangerous work sectors with a high accident record. The use of heavy machinery, unsafe working conditions, and hazardous materials handling is among the causes of many work-related accidents recorded among factory workers. In addition, the lack of safety training and low safety management commitment towards worker safety also contributed to the increasing number in this statistic. The goal of this investigation is to determine the link between management commitment and safety training on safety behaviour among workers. This study involved small and medium factory workers operating in the northern states of peninsular Malaysia. The data for this study was obtained using a questionnaire, while the Statistical Packages for Social Science (SPSS) application was used to perform the data analysis process. The results of the data analysis show that employers' commitment to safety and safety training has a positive relationship with safety behaviour among study respondents. Suggestions and improvements to the study are presented at the end of this writing. 


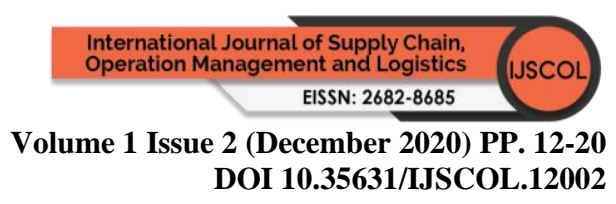

DOI: $10.35631 /$ IJSCOL.12002

This work is licensed under $\mathrm{CC}$ BY 4.0

Keywords:

()ㅜㅇ

Worker, Safety Training, Management Commitment, Safety Behaviour, Small And Medium Factory

\section{Introduction}

A safer workplace is essential element to the continuous operation and survival for any organisations. Development and nesting a safer workplace should be the highest priority within the organizations. This situation depends on the roles of management and their workers in creating a safe work environment. As employers, they have an obligation to develop and maintain an effective safety promotion programs that comply with the OSHA 1994 requirement. However, hang up a safety poster and run few safety programs once a year is not enough if no positive work safety culture has been cultivated in the organization. Safety culture refers to "the outcomes of individual and group values, attitudes, perceptions, competencies, and patterns of behaviour that determine the commitment to, and the style and proficiency of, an organisation's health and safety management" (Health and Safety Executive [HSE], 1993). Understanding the factors influenced the safety culture within the organisation can be a noteworthy feature in understanding employees' safety behaviours and their influence on the workplace safety performance. The main target of this research is to investigate the link between management commitment and safety training on worker safety behaviour.

\section{Literature Review}

For almost all countries in the world, small and medium enterprises (SMEs) is vital for economy, particularly in developing countries like Malaysia. The sector is considered the backbone of the Malaysian economy, leading to country industrial production (98.5\%), exports (17.9\%), employing about $48.4 \%$ of Malaysians, generating 7.3 million jobs per year, and manufacturing more than 8,000 products for the Malaysian and foreign markets. SMEs alone contribute to 38.9\% of the Malaysian gross domestic product (GDP) (Department of Statistics Malaysia [DOSM], 2019). Many factors are responsible for the growth of small and mediumsized enterprises in Malaysia, including funding for small and medium-sized enterprises, new technology, and various trade directories and trade portals. 5.3 percent of companies are involved in manufacturing, while 89.2 percent of companies are involved in services. In 2016, 907,065 companies were reported to be the total number of companies in the SME market, of which $76.5 \%$ were registered as micro-enterprises, $21.2 \%$ were small enterprises, and $2.3 \%$ were medium-sized enterprises (DOSM, 2019).

The manufacturing sector is characterised as work environment with a poor safety performance compare with other industries. In Malaysia, the manufacturing sector leads to about 4 percent of all industrial accidents. An average of 80 employees have been killed in incidents per year (Abas et al., 2013). Although the implementation of self-regulation, through the adoption in 1994 of the Occupational Safety and Health Act (OSHA), the number of occupational injuries in this segment of the economy is still high. However, very limited information indicated the actual number of occupational accidents happen in small and medium-sized manufacturing companies.

Maintaining a positive safety work environment in an SME companies is not always an easy task. To perform safely, the organization needs to set safety as their main priority in their daily 


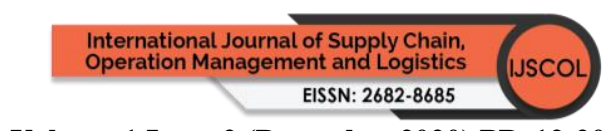

Volume 1 Issue 2 (December 2020) PP. 12-20 DOI 10.35631/IJSCOL.12002

business. Still, this issue always seen as long-term operational burden and inconsequential matter within the SME's. The size of the SME companies, human capital available and the financial factors drifted their intention on the SME's safety activities.

Due to that, an intensive investigation on workers safety behaviour and its major determinants will help small and medium-sized manufacturing companies in identifying an effective means to reduce potential future accident in their workplace with strategically allocate resources and concentrate their efforts to ensure the improvement of their overall safety performance.

\section{Safety Behaviour}

Worker behaviours towards safety are the main 'ingredient' that binds everything together to create safer workplace. Safety behaviour is positive behaviour by worker toward safety while working. Examples of positive safety behaviour among worker is wearing PPE's, follow the SOP's and comply with safety rules. Positive safety behaviour among worker will lead to low accident statistic with minimal injuries and loss.

In other hand, if an 'unsafe' behaviour become a norm in the organization, it will lead to unwanted accidents that may cause to injuries and fatalities. At the end, the worker might suffer physically and emotionally. The ruination occurs when the management fail to recognize this problem among their worker and often acknowledge the unsafe behaviour is part of work practice.

Previous study proof that various safety management practices (such as management commitment, safety training, safety communication, etc.) has a significant contribution on maintaining positive safety behaviour (Trinchero et al., 2017; Yorio \& Wachter, 2014; Flin, 2017; Lin et al., 2017; Brunetto, et al., 2016; Kapp \& Han, 2017; Subramaniam et al., 2016). The aims of this investigation are to analyse the relationship between the management commitment and safety training to employee safety behaviour in small and medium-sized manufacturing enterprises in northern Peninsular Malaysia.

\section{Management Commitment}

Management commitment is a term frequently use to defined management involvement and participation in organization safety programs. In the earliest safety investigation, researchers discovered that management commitment on workplace safety is an important antecedence in influencing the effectiveness of an organization's safety initiatives programs.

To have high committed safety management commitment, all management team members should be united in their way of thinking about safety and integrate it into their organisation's strategic decision-making processes. The management commitment on safety must been show in an observable activity by the management and must be demonstrated in their behaviour as well as their words (Alam et al., 2020, Abdullah \& Abdul Aziz, 2020). Safety policy statement is one of solid example of management commitment on safety.

\section{Safety Training}

Safety training always been a main successful contributor to an accident prevention programme in any organization. It a process that provide skills and knowledge to the worker to work safely while performing their task. A proper plan of safety training can stimulate a positive safety 


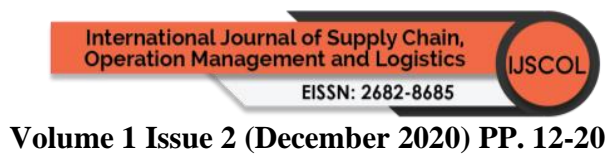

DOI 10.35631/IJSCOL.12002

behaviour among workers. Thru safety training, workers able to recognize the hazards and minimize it before it became disaster.

Organizations should create a formal, rigorous, and comprehensive safety training program for all their employees (Guo et al., 2016; Flin, 2017; Lin et al., 2017). It should start by identifying the safety training needs, set a safety training objective, select the training method, and implement the best safety training method that suit with the company needs and budget. Therefore, the management should also consider it as part of partial in their operational budget. This study aims to investigate the relationship between management commitment and safety training on safety behaviour among workers. Based on above justification, this study proposed the research framework as in Figure 1.

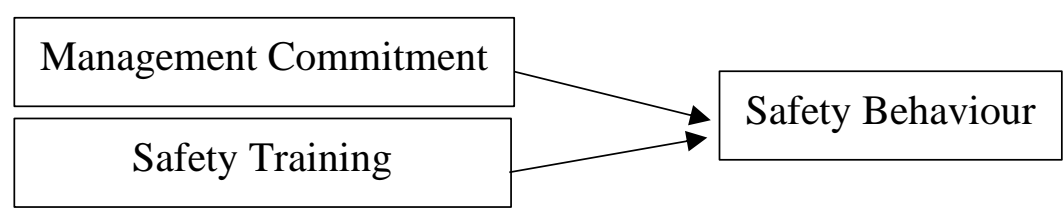

Figure 1: Research Framework

$\mathrm{H}_{1}$ Management commitment has positive relationship with safety behaviour $\mathrm{H}_{2}$ Safety training has positive relationship with safety behaviour

\section{Methodology}

This is a correlational study that employed to identify the link between independent variable and dependent. To gather valuable data to fulfil the objectives of this research, a quantitative method was employed. Structured questionnaire was used to gather data. For this study, a total of 47 items in the questionnaire were adopted from the previous studies.

The study was conducted among workers in small and medium-sized manufacturing companies operating in the Northern region (Perlis, Kedah, Penang, and North Perak). A convenience sampling was proposed to execute the proposed study. The convenience sample help the researchers to collect research information after several hindrance occurred during the data collection process. For example, late approval from the selected company to participate in this research. Moreover, the relative cost and time required for convenience sampling also give other reason for researchers to use this technique.

The sample size was calculated based on the suggestion by Roscoe Rule of Thumb (1975) as cited in Sekaran \& Bougie (2013). However, to take care of non-responses that might affect the required sample size, this research decided to increase the sample size to 500. At end of data collection period, a sum of 402 questionnaires returned to the researchers. Only 382 questionnaires were used in data analysis process, other rejected due to incomplete issues.

Statistical Package for the Social Sciences (SPSS) was utilised to analyse the data. The analysis includes descriptive statistical analyses and hypotheses testing analyses. Pilot test was conducted prior the actual data collecting even though the instruments been validated from earliest studies. The reliability results for each variable ranged from 0.604 to 0.893 , which are 
generally considered acceptable for research purposes as recommend (Sekaran \& Bougie, 2013).

\section{Results of the Data Analysis}

The total number of respondents consisted of 137 men and 245 women. Most of the respondents ( 81.5 percent) were married and 44.2 percent were 20 to 30 years old. The majority (85.9 percent) reported earnings below RM1000 per month in terms of salary range. Just $25.7 \%$ suggested they had to function in shifts.

The model summary is represented by Table 1 . The $R$-value is 0.685 and the $R^{2}$-value is 0.469 , which demonstrates a strong linear regression between variables. This value shows that 46.9 percent of the variance in safety behaviour was explained by the interaction with independent variables that been investigated.

Table 1: Model Summary

\begin{tabular}{ccccc}
\hline Model & $R$ & $R^{2}$ & Adjusted $R^{2}$ & Std. Error of the Estimate \\
\hline 1 & 0.685 & 0.469 & 0.466 & 5.90820 \\
\hline
\end{tabular}

Table 2 displays the regression for significant factors correlated with safety behaviour.

Table 2: Regression and Related Statistics

\begin{tabular}{lllllll}
\hline & & \multicolumn{2}{l}{$\begin{array}{l}\text { Unstandardised } \\
\text { Coefficients }\end{array}$} & $\begin{array}{l}\text { Standardised } \\
\text { Model } \\
\text { Coefficients }\end{array}$ & \\
\hline Model & & B & Std. Error & B & $T$ & Sig \\
\hline 1 & $\begin{array}{l}\text { (Constant) } \\
\text { Management }\end{array}$ & 1.376 & 3.100 & & 0.444 & 0.657 \\
& $\begin{array}{l}\text { Commitment } \\
\text { Safety Training }\end{array}$ & 0.686 & 0.043 & 0.664 & 16.105 & 0.000 \\
& & 0.321 & 0.113 & 0.111 & 2.765 & 0.006 \\
\hline
\end{tabular}

The hypothesis testing indicated that management commitment and safety training has a significantly associated with workers safety behaviour. Based on the result, the management commitment has stronger relationship with safety behaviour compare to safety training. This finding is consistent with the result of past studies that proved a significant relationship between management commitment and safety training on worker safety behaviour (Osman et al., 2019; Abdullah \& Abd Aziz, 2020; Panuwatwanich et al., 2017; Yean et al, 2020).

\section{Discussion and Recommendation}

The findings of the study revealed that management commitment is positively associated with the safety behaviour among respondents. Management commitment to safety has been as main antecedent to the accomplishment of safety promotion activities in the organization. The top management's commitment is consequently important to any safety performance success. There is a significant evidence that management commitment is one of the main elements in reducing accidents at work (Vinodkumar \& Bhasi, 2010). 


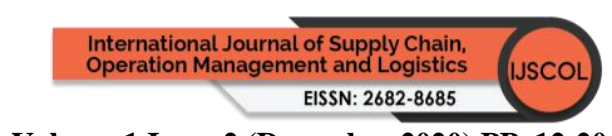

Volume 1 Issue 2 (December 2020) PP. 12-20

DOI 10.35631/IJSCOL.12002

Management commitment on safety involve management teams that include all rank of executives in the organization. They can be chairman, CEO, presidents, senior manager, middle manager, line manager and supervisor. Broadly speaking, top-rank management team like chairman, president, vice-president, general manager etc. play their roles in setting the vision, mission, and objective for safety excellence. The commitment of top-rank management regarding safety means they must endow necessary financial and resources to accomplish the safety vision. They can demonstrate commitment to safety through effective involvement in safety activity in the organization like attend safety meeting, involve in safety audit and personally monitor the safety of the workplace to visibly show their involvement.

For middle management teams such as line manager, branch manager and supervisor, their task in safety management commitment is to facilitate the execution of the safety vision, mission and objective that been determine by the top-rank management. All manager in this level are in-charge to make sure the performance of their subordinates meets the safety standard and align with safety statement made by the top management, i.e. reducing the accident and injury rate. The middle management teams also need to physically be committed by demonstrating their involvement in safety management programs.

They can perform their roles in communicating the top management safety expectations to their subordinates, monitoring and measuring subordinate's safety performance, sculpting a positive safety behaviour in the workplace and leading incident and accident investigations team as an effort to prevent future unwanted situation.

The hypothesis suggests that there is a positive association between safety training and workers safety behaviour. Most of the respondents agreed that their employers fulfil their management obligations by providing them with safety training. This situation indicated the positive safety management practices in their workplace. The important role of safety training in promoting safety behaviours among employees has been recognised by management of studied companies. Even though this program eats a lot of financial allocation, the management still provides the basic safety training for their employee as their fulfilment to OSHA 1994. This finding supported by the past research outcome that indicated a positive and significant association between safety training and safety behaviour (Guo et al., 2016; Flin, 2017; Lin et al., 2017).

Safety training programs gives employees an opportunity to learn how to perform their jobs properly, reinforce existing safety work practices, and helps to push organization safety performance. As mentioned above, each company should provide a necessary funds, resources, manpower and time to ensure effective safety training programs. All parties (management and employees) will be involved in developing the safety training program. First stage in safety training plan is determining safety training needs. In this stage, the management will determine the people who need for safety training, the type of job that need safety training and the level of organization that require safety training program. An observation, survey and trend analysis on past accident and incident cases will be the useful information in answering those questions.

Based on the above details, the safety training objective can be set. The objective will be the target that training participant must attain at the end of the program. Most of the safety objective training is to give a certain skill that will help the worker to perform their task safely with any hazardous risks. There also a specific training skills that should be provided to certain people 


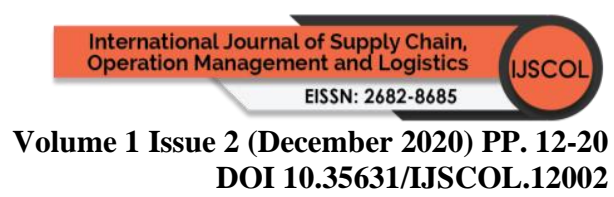

in the company like training for all managers, supervisors and employees on their safety management system responsibilities; training for investigation team members on hazard identification, analysis, reporting and control procedures; and training recues aiders on emergency work procedures and practices.

The safety training method and provider also need to be considered in the next stage of safety training plan. As small and medium-sized company, the cost should be the main constraint in developing their own safety training program. They must be smart in selecting the most suitable safety training method and provider that complement with their budget. There are plenty of safety training videos in online video-sharing platform, the organization only have shared the link a to their employees as part of safety training method and it also is free.

After the method and provider of the safety training was decided, then the company can execute the programs. The result of the safety training should be evaluated to assure the target been achieved. The outcome can be in accident reduction rate; productivity and quality improvement; less medical and insurance claims; low turnover and absenteeism; reduced stress; and higher morale among workers.

This research contributes to the existing literature in several important ways. First, the present study had fulfilled the gap by examining the effects of management commitment and safety training on safety performance. Second, this research has provided a theoretical implication by giving additional empirical evidence in the domain of social cognitive theory, which posits that a positive state of mind in the form of safety management will promote positive work behaviour and enhance company safety performance. This research has extended the application of theory by examining the aforesaid relationship with the samples withdrawn from SMEs. This is vital because focusing on a different research setting may expand the practicality of the theory. Third, the findings of this research also provide useful information to the present and future employers. This is crucial because employers are extensively involved in the development of positive safety behaviour for their organisation. Therefore, the management of SMEs, especially the owner of the company may consider redesigning the work environment through safety-orientated climate to facilitate the opportunity to the workers to work positively towards safety.

Regarding the study limitation, this study is limited by its self-reported instrument. The main limitation of self-reported instrument is that there are a few potential validity problems associated with it. Another limitation is the data for the study were collected at a single point in time. Besides that, the data of this study were gathered only through questionnaire. Thus, the feedback depends on the voluntary cooperation of the academics. Further, the responses may not be a consistent and accurate measure of work behaviours since respondents may be biased in answering the questions to project their good image. Therefore, to enhance the precision of findings, quantitative and qualitative methods of research could be incorporated in the future studies.

In summary, the purpose of this study was to test the relationship between management commitment, safety training, and safety behaviour. Despite the limitations discussed previously, this study has the potential to make significant contribution to safety research and practice. The findings of the significant influence of management commitment and safety training on safety behaviour demonstrates the importance of workplace safety practices within 


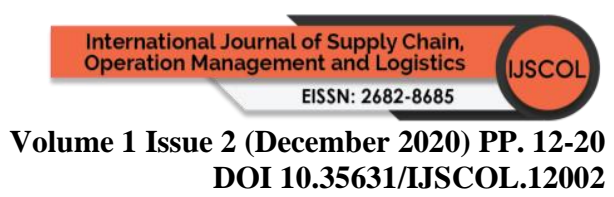

organisation, particularly among SMEs in Malaysia. Organizations need to actively nurture a strong and positive safety culture all year-round and make it as company DNA. Organization should ensure safety as one of the organization's main values and constantly striving to improve it in the workplace.

\section{Acknowledgement}

This paper is part of the findings of a study entitled "Validating the safety culture model in SME manufacturing companies in Malaysia" under the Fundamental Research Grant Scheme (FRGS), Ministry of Higher Education Malaysia (MOHE) (S.O. Code: 12365). Therefore, the researcher would like to thank the MOHE, the top management of Universiti Utara Malaysia (UUM) and Research and Innovation Management Centre (RIMC), UUM for the contribution of funds and support to enable this study to be conducted.

\section{References}

Abas, A. L., Said, A. R. M., Mohammed, M. A. A. \& Sathiakumar, N. (2013). Non-fatal Occupational Injuries among Non-governmental Employees in Malaysia. American Journal of Industrial Medicine. 56(1), 38048.

Abdullah, K. H., \& Abd Aziz, F. S. (2020). Safety Behaviour in the Laboratory among University Students. The Journal of Behavioral Science, 15(3), 51-65.

Alam, S., Chowdhury, S. R., Bashar, A., \& Hoque, M. A. (2020). Factors Affecting Occupational Injury and Death: Insights from Ready-Made Garments Industry of Bangladesh.

Brunetto, Y., Xerri, M., Farr-Wharton, B., Shacklock, K., Farr-Wharton, R., \& Trinchero, R. (2016). Nurse safety outcomes: old problem, new solution-the differentiating roles of nurses psychological capital and managerial support. Journal of Advanced Nursing, 72(11), 2794-2805.

Department of Statistics Malaysia [DOSM], (2019). SME Statistics. Retrieved from https://www.smecorp.gov.my/index.php/en/policies/2020-02-11-08-01-24/smestatistics

Flin, R. (2017). Enhancing safety performance: Non-technical skills and a modicum of chronic unease. In C. Bieder, C. Gilbert, B. Journé, \& H. Laroche (Eds.), Beyond Safety Training. SpringerBriefs in Applied Sciences and Technology (pp.45-58). Cham: Springer.

Guo, B.W., Yiu, T.W., \& Gonzalez, V.A. (2016). Predicting safety behaviour in the construction industry: Development and test of an integrative model. Safety Science, $84,1-11$

Health and Safety Executice, (1993). ACSNI Study Group on Human Factors. Third report: Organising for safety. In Advisory Committee on the Safety of Nuclear Installations (1993). Retrieved from https://www.hse.gov.uk/humanfactors/topics/common4.pdf.

Kapp, A.E., \& Han, A.A. (2017). Integrating health with safety: Now is the time. Professional Safety, 65(5), 44-49.

Lin, Y.S., Lin, Y.C., \& Lou, M.F. (2017). Concept analysis of safety climate in healthcare providers. Journal of Clinical Nursing, 26(11), 1737-1747.

Osman, A., Khalid, K., \& AlFqeeh, F. M. (2019). Exploring the role of safety culture factors towards safety behaviour in small-medium enterprise. International Journal of Entrepreneurship, 23(3), 1-11.

Panuwatwanich, K., Al-Haadir, S., \& Stewart, R. A. (2017). Influence of safety motivation and climate on safety behaviour and outcomes: evidence from the Saudi Arabian 
construction industry. International journal of occupational safety and ergonomics, 23(1), 60-75.

Sekaran, U., \& Bougie, R. (2013). Research methods for business: A skills-building approach (6th ed.). West Sussex: Wiley.

Subramaniam, C., Shamsudin, F. M., Zin, M. L. M., Ramalu, S. S., \& Hassan, Z. (2016). Safety management practices and safety compliance in small medium enterprises: Mediating role of safety participation. Asia-Pacific Journal of Business Administration, 8(3), 226244.

Trinchero, E., Farr-Wharton, B., \& Brunetto, Y. (2017). Workplace relationships, psychological capital, accreditation and safety culture: A new framework of analysis within healthcare organizations. Public Organization Review, 1-14.

Vinodkumar, M., \& Bhasi, M. (2010). Safety management practices and safety behaviour: Assessing the mediating role of safety knowledge and motivation. Accident Analysis \& Prevention, 42(6), 2082-2093.

Yuen, K. F., Li, K. X., Ma, F., \& Wang, X. (2020). The effect of emotional appeal on seafarers' safety behaviour: An extended health belief model. Journal of Transport \& Health, 16, 100810.

Yorio, P.L., \& Wachter, J.K. (2014). The impact of human performance focused safety and health management practices on injury and illness rates: Do size and industry matter? Safety Science, 62, 157-167. 